\title{
Healthy hire effect, job selection and inhalation exposure among young adults
} with asthma

\author{
M. Olivieri, M.C. Mirabelli, E. Plana, K. Radon, J.M. Antó, P. Bakke, G. Benke, \\ A. D’Errico, P. Henneberger, H. Kromhout, D. Norbäck, K. Torén, M. van Sprundel, \\ S. Villani, G. Wieslander, J-P. Zock and M. Kogevinas
}

ABSTRACT: The aim of the present study was to assess whether asthma onset prior to entering the workforce influences whether a person holds a subsequent job with asthma-related inhalation exposures.

The data of 19,784 adults from the European Community Respiratory Health Survey were analysed. For each respondent, a current or previously held job was linked to a job exposure matrix assigning high, low or no exposure to dust, gases or fumes. Jobs were also categorised according to the risk of exposures related to occupational asthma. Associations between asthma and subsequent occupational exposures were assessed using logistic regression models, with a random intercept for study centre and fixed adjustment for age, sex, type of study sample and smoking status.

Of the respondents, $8 \%(n=1,619)$ reported asthma with onset before completion of full-time education. This population was at decreased risk of having a job with high (odds ratio $0.79 ; 95 \%$ confidence interval $\mathbf{0 . 6 8 - 0 . 9 2 )}$ or low $(0.91 ; 0.80-1.03)$ exposure to dust, gases or fumes. The associations were consistent across exposure types (dusts, gases or fumes) and for jobs with a high risk of occupational asthma.

Adults with asthma onset prior to entering the workforce may be less likely to hold jobs involving inhalation exposures.

KEYWORDS: Asthma, cross-sectional study, healthy worker effect, occupational exposure

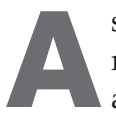
sthma affects people of all ages, and respiratory symptoms associated with asthma contribute substantially to morbidity and mortality in adults in the industrialised world. Although the onset of asthma often occurs during childhood, some people first develop symptoms during adult life. Workplace exposures are associated with adult-onset asthma [1], and it has been estimated that 15\% (median; range $4-58 \%$ ) of adult asthma cases may be related to occupation [2]. In addition to the clear causal relationship between occupational exposures and symptoms of asthma, the possibility also exists that asthma symptoms may influence job choice, work tasks or occupational inhalation exposures.

In occupational health research, an observed reduction in morbidity and mortality among workers relative to the general population has been explained as an expression of the healthy worker effect [3-8]. Specifically, the healthy worker effect is observed when individuals who are sick or more sensitive are excluded from being hired or avoid work involving hazardous exposures because of their health status [8]. Since asthma may occur during childhood or adulthood, the healthy worker effect can be seen as two distinct phenomena affecting the observed prevalence of respiratory symptoms in the working population relative to the general population. First, if adult-onset asthma causes symptomatic adults to leave jobs with hazardous inhalation exposures, then the phenomenon observed may be that asymptomatic workers survive longer in these exposed jobs. Secondly, if onset of asthma before entering the workforce results in fewer symptomatic individuals performing jobs with inhalation exposures, then the decreased prevalence of symptomatic workers may be due to selfselection and the hiring of a healthier workforce (i.e. the healthy hire effect). Despite increased attention paid to the relationship between occupational exposures and asthma, the healthy hire
AFFILIATIONS

For affiliations, please see the Acknowledgements section.

CORRESPONDENCE

M. Olivieri

Dept of Medicine and Public Health Unit of Occupational Medicine, University Hospital of Verona University of Verona 37129 Verona Italy E-mail: mario.olivieri@univr.it

Received: Aug 062009 Accepted after revision: Feb 102010 First published online: Feb 252010 
effect is not often evaluated with respect to pre-existing respiratory symptoms and subsequent inhalation exposures.

European Community Respiratory Health Survey (ECRHS) I was conducted to assess the prevalence of asthma and its known or suspected risk factors in a large number of countries using a standardised protocol [9]. This survey of young adults in Western European and other industrialised countries collected information about respiratory health and occupation from random samples of the general population. Data from this survey were analysed in order to assess whether or not a history of asthma with onset before completion of full-time education was associated with holding a subsequent job with inhalation exposures or with increased risk of occupational asthma.

\section{METHODS}

The ECRHS is an international population-based study of males and females aged 20-44 yrs. Its methods have been described previously [9]. For the present analysis, questionnaire data were available for 23,064 participants from 40 study centres in 18 countries in which the study protocols included a survey question about full-time education and coding of the reported occupation. The data included in this analysis are from Northern Europe (Denmark, Iceland, Norway and Sweden), Central Europe (Belgium, Germany, Ireland, the Netherlands, Poland and the UK), Southern Europe (France, Italy and Spain) and other areas (Australia, Canada, New Zealand and the USA).

\section{Asthma onset and completion of full-time education}

Participants were classified as having asthma if they answered "yes" to the survey question "have you ever had asthma?" Asthma onset was determined using responses to the followup question "if yes, how old were you when you had your first attack of asthma?" Age at completion of full-time education was identified among respondents who answered "no" to the question "are you a full-time student?" and answered the follow-up question "at what age did you complete full-time education?" Participants who indicated that they were fulltime students at the time that they completed the survey were considered to have not yet completed full-time education and were excluded from this analysis $(n=1,747)$ because they were not eligible to be classified according to their occupational exposure status, which is the primary outcome in these analyses. For the same reason, participants for whom asthma status prior to completion of full-time education was unknown were also excluded $(n=463)$, resulting in a final sample of respondents reporting onset of asthma prior to completion of full-time education and respondents who had never had asthma or whose asthma onset occurred after the completion of full-time education.

\section{Occupational exposure assessment}

All respondents who were not full-time students and were either employed or self-employed at the time of the survey were asked to identify their current or most recent job. Although a job history was not included in the questionnaire, these respondents were then asked two questions in order to provide additional information about their previous work experiences. All respondents were asked "have you ever had to change or leave your job because it affected your breathing?" Those with a positive response to this question were then asked "what was this job?" Respondents were also asked "have you ever worked in a job that exposed you to vapours, gas, dust or fumes?" Those with a positive response were prompted "what was or is this job?" For individuals who had changed or left an identified job because of its impact on breathing or who had worked in a job with exposure to vapours, gases, dusts or fumes, the current/most recent job was replaced with the job held earlier. Among the respondents, 1,070 provided insufficient information about current, most recent or earlier job(s) and were excluded from the final sample.

Each participant's job was coded using the Office of Population Censuses and Surveys 1980 classification system [10]. Codes were then linked to a general population job exposure matrix (JEM) $[11,12]$ in order to assess likely exposure to biological dust, mineral dust and gases or fumes. Application of the JEM resulted in assignment of each job into semi-quantitative exposure categories, including high exposure, low exposure and unexposed $[12,13]$. In addition, in order to identify jobs with known or suspected increased risk of occupational asthma, a modified version of a classification scheme previously used for analysis of ECRHS data was applied [13]. The modification of the classifications used in KoGEVINAS et al. [13] resulted in occupations being identified as high risk (agriculture and forestry, baking, cleaning and caretaking, chemical processing, electrical processing, hairdressing, metalworking, nursing, plastics or rubber industries, printing, spray painting and other painting, and welding) or not high risk (professional, clerical and administrative occupations). Occupations involving potential airborne exposure but not included in the highrisk category were defined as jobs with possible risk.

\section{Statistical analysis}

All analyses were performed with a final sample of 19,784 individuals. Odds ratios (ORs) for associations between onset of asthma before completion of full-time education and occupational exposure estimates were generated using logistic regression models. In all models, asthma onset before completion of full-time education (yes versus no) was the independent variable; dependent variables were the exposure categories assigned using either the JEM or the occupation/industry classification of jobs with high risk of occupational asthma. All models were specified with random intercepts for study centre and fixed adjustment for age, sex, type of study sample (random versus symptomatic) [9] and smoking status (lifetime nonsmoker, former smoker, current smoker and unknown smoking status) at the time that the respondent completed their full-time education.

Meta-analyses were conducted to assess the heterogeneity of effects among countries, and analyses were stratified to assess potential modification of the associations by sex, geographical area and histories of eczema, nasal allergies, parental asthma and respiratory infection before the age of 5 yrs. Sensitivity analyses were then conducted to assess whether or not the results of the final models varied when the referent category was restricted first to individuals with no history of asthma $(n=17,209)$ and then to those whose asthma onset occurred after they had completed their full-time education $(n=956)$. Statistical analyses were performed using Stata/SE 10.0 (Stata Corporation, College Station, TX, USA). 


\section{RESULTS}

The demographic and health characteristics of the final study population are presented in table 1 . Of the 19,784 respondents included in the present analysis, $13.0 \%(n=2,575)$ reported having had asthma, with age of onset ranging 0-45 yrs (mean 15.6 yrs). Over half of the respondents with asthma reported that onset had occurred prior to completion of full-time education $(n=1,619)$; this group included a higher percentage of males and a higher percentage of individuals in the highest country-specific tertile of education as compared to the remaining population. Eczema, nasal allergies/hay fever, parental asthma and respiratory infection before the age of 5 yrs were each more common among participants whose asthma onset occurred before they had completed their full-time education $(p<0.01)$. Smoking status at completion of full-time education was similar in populations with and without asthma.

The classification of occupational exposure to biological dust, mineral dust, gases or fumes and high-asthma-risk occupations was based on jobs that respondents reported changing or leaving because the jobs affected their breathing $(n=820 ; 4.1 \%)$ or involved exposure to vapours, gas, dust or fumes $(n=8,794$; $44.5 \%)$. The remaining jobs $(n=10,170 ; 51.4 \%)$ were those held by respondents at the time of the ECRHS I survey. Over half of the participants held jobs with low or high exposure to biological or mineral dust, gases or fumes. Overall, $6.4 \%$ $(n=1,270)$ of respondents' jobs involved high exposure to biological dust, $11.0 \%(n=2,146)$ to mineral dust, $13.0 \%$ $(n=2,664)$ to gases or fumes, and $22.0 \%(n=4,289)$ to dust, gases or fumes (table 2). Using a priori classifications of occupation, the jobs of $6,465(33.0 \%)$ respondents were classified as high risk for occupational asthma. Adjusted associations indicate a lower risk of high occupational exposure to dusts, gases or fumes among individuals with asthma presenting before completion of full-time education (OR 0.79; 95\% confidence interval (CI) 0.68-0.92). Evaluation of the risk of occupational exposure based on a priori asthma risk classification also generated inverse associations for the risk of working in occupations with known high risk $(0.85 ; 0.75-0.97)$ and possible risk $(0.82$; CI $0.70-0.96)$ for asthma.

Analyses stratified by sex and across geographical regions generated similar sex-specific ORs for the association between asthma onset before completion of full-time education and high exposure to dust, gases or fumes (males: OR 0.77; 95\% CI $0.63-$ 0.94; females: OR $0.82 ; 95 \%$ CI $0.64-1.04)$, and geographical variation that ranged from 0.58 (95\% CI 0.42-0.79) among Central European countries to 0.95 (95\% CI 0.75-1.20) among non-European countries. Country-specific associations between asthma onset and high exposure to dust, gases or fumes and high-risk occupations are shown in figure 1. Analyses stratified by history of eczema, nasal allergies, parental asthma or respiratory infection before the age of $5 \mathrm{yrs}$ and analyses stratified by the number of these conditions in the respondents' health histories (i.e. none, one, two, three or more) did not generate consistent evidence of modification of the effects by health history.

Analyses restricted to respondents with asthma onset prior to completion of full-time education versus those with no history of asthma generated results similar to those shown in table 2. In these analyses, the population with asthma onset prior to

\begin{tabular}{|c|c|c|c|c|}
\hline \multirow[t]{2}{*}{ TABLE 1} & \multicolumn{4}{|c|}{$\begin{array}{l}\text { Characteristics of the study population by onset } \\
\text { of asthma prior to completion of full-time } \\
\text { education (FTE) }\end{array}$} \\
\hline & & Total & No onset & Onset \\
\hline Subjects $n$ & & 19784 & 18165 & 1619 \\
\hline \multicolumn{5}{|c|}{ Age, education and asthma onset } \\
\hline Age at ECF & HS I yrs & $33.6 \pm 6.9$ & $33.7 \pm 6.8$ & $31.9 \pm 6.8$ \\
\hline Age at com & letion of FTE yrs & $19.7 \pm 4.4$ & $19.6 \pm 4.4$ & $20.4 \pm 4.8$ \\
\hline \multicolumn{5}{|c|}{ Educational level ${ }^{\#}$} \\
\hline High & & 5657 (28.6) & $5084(28.0)$ & $573(35.4)$ \\
\hline Medium & & $6066(30.7)$ & $5547(30.5)$ & $519(32.1)$ \\
\hline Low & & 7782 (39.3) & 7255 (39.9) & 527 (32.6) \\
\hline Unknowr & & $279(1.4)$ & $279(1.5)$ & $0(0.0)$ \\
\hline \multicolumn{5}{|c|}{ Ever had asthma } \\
\hline No & & $17209(87.0)$ & $17209(94.7)$ & $0(0.0)$ \\
\hline Yes & & $2575(13.0)$ & $956(5.3)$ & $1619(100.0)$ \\
\hline Age at first & sthma attack yrs & $15.6 \pm 11.8$ & $28.2 \pm 7.1$ & $8.2 \pm 6.7$ \\
\hline \multicolumn{5}{|c|}{ Other demographic characteristics } \\
\hline \multicolumn{5}{|c|}{ Geographical region } \\
\hline Northern & urope & 3819 (19.3) & 3485 (19.2) & $334(20.6)$ \\
\hline Central E & rope & $7174(36.3)$ & $6736(37.1)$ & $438(27.1)$ \\
\hline Southern & Europe & $3483(17.6)$ & $3293(18.1)$ & $190(11.7)$ \\
\hline Non-Eurc & ean countries & $5308(26.8)$ & $4651(25.6)$ & $657(40.6)$ \\
\hline \multicolumn{5}{|l|}{ Sex } \\
\hline Male & & $9463(47.8)$ & $8603(47.4)$ & $860(53.1)$ \\
\hline Female & & $10321(52.2)$ & $9562(52.6)$ & 759 (46.9) \\
\hline \multicolumn{5}{|c|}{ Health history } \\
\hline \multicolumn{5}{|l|}{ Eczema } \\
\hline No & & $11871(60.0)$ & $11117(61.2)$ & $754(46.6)$ \\
\hline Yes & & $7644(38.6)$ & $6789(37.4)$ & $855(52.8)$ \\
\hline Unknowr & & $269(1.4)$ & $259(1.4)$ & $10(0.6)$ \\
\hline \multicolumn{5}{|c|}{ Nasal allergies/hay fever } \\
\hline No & & 13767 (69.6) & $13210(72.7)$ & 557 (34.4) \\
\hline Yes & & $5732(29.0)$ & 4682 (25.8) & $1050(64.9)$ \\
\hline Unknowr & & $285(1.4)$ & $273(1.5)$ & $12(0.7)$ \\
\hline \multicolumn{5}{|c|}{ Parental asthma } \\
\hline No & & 15510 (78.4) & 14487 (79.8) & $1023(63.2)$ \\
\hline Yes & & 2475 (12.5) & 2030 (11.2) & 445 (27.5) \\
\hline Unknowr & & 1799 (9.1) & $1648(9.1)$ & 151 (9.3) \\
\hline \multicolumn{5}{|c|}{ Respiratory infection aged $<5 \mathrm{yrs}$} \\
\hline No & & $16173(81.8)$ & $15223(83.8)$ & $950(58.7)$ \\
\hline Yes & & $2108(10.7)$ & $1640(9.0)$ & 468 (28.9) \\
\hline Unknowr & & $1503(7.6)$ & $1302(7.2)$ & $201(12.4)$ \\
\hline \multicolumn{5}{|c|}{$\begin{array}{l}\text { Smoking status at completion } \\
\text { of FTE }\end{array}$} \\
\hline Never & & 12250 (61.9) & $11215(61.7)$ & $1035(63.9)$ \\
\hline Former & & $781(4.0)$ & $692(3.8)$ & $89(5.5)$ \\
\hline Current & & $6420(32.5)$ & 5957 (32.8) & $463(28.6)$ \\
\hline Unknowr & & $333(1.7)$ & $301(1.7)$ & $32(2.0)$ \\
\hline
\end{tabular}

completion of full-time education was at decreased risk of having a job with high (OR $0.79 ; 95 \%$ CI $0.67-0.92)$ or low $(0.90$; 0.79-1.03) exposure to dust, gases or fumes and working in occupations with known high risk $(0.87 ; 0.76-0.98)$ and 


\begin{tabular}{|c|c|c|c|c|}
\hline \multirow[t]{2}{*}{ TABLE 2} & \multicolumn{4}{|c|}{$\begin{array}{l}\text { Associations between asthma onset prior to } \\
\text { completion of full-time education and } \\
\text { occupational exposure among } 19,784 \text { European } \\
\text { Community Respiratory Health Survey I } \\
\text { participants }\end{array}$} \\
\hline & & No onset & Onset & OR $(95 \% \mathrm{Cl})^{\#}$ \\
\hline Subjects $\mathrm{n}$ & & 18165 & 1619 & \\
\hline \multicolumn{5}{|c|}{ JEM classification } \\
\hline Unexposed & & $8302(46)$ & $737(46)$ & 1.00 \\
\hline \multicolumn{5}{|c|}{ Biological dust } \\
\hline Low & & $2829(16)$ & $236(15)$ & $0.84(0.72-0.99)$ \\
\hline High & & $1147(6)$ & $123(8)$ & $0.92(0.74-1.16)$ \\
\hline \multicolumn{5}{|l|}{ Mineral dust } \\
\hline Low & & $4158(23)$ & $388(24)$ & $0.88(0.76-1.02)$ \\
\hline High & & $1978(11)$ & $168(10)$ & $0.75(0.62-0.91)$ \\
\hline \multicolumn{5}{|c|}{ Gases or fumes } \\
\hline Low & & $5173(28)$ & $463(29)$ & $0.89(0.78-1.01)$ \\
\hline High & & $2460(14)$ & 204 (13) & $0.76(0.64-0.91)$ \\
\hline \multicolumn{5}{|c|}{ Any combination of above } \\
\hline Low & & 5921 (33) & 535 (33) & $0.91(0.80-1.03)$ \\
\hline High & & 3942 (22) & $347(21)$ & $0.79(0.68-0.92)$ \\
\hline \multicolumn{5}{|c|}{$\begin{array}{l}\text { Classification as high-risk } \\
\text { occupation }^{+}\end{array}$} \\
\hline No & & 8919 (49) & 800 (49) & 1.00 \\
\hline Yes & & 5931 (33) & 534 (33) & $0.85(0.75-0.97)$ \\
\hline Possible & & 3315 (18) & 285 (18) & $0.82(0.70-0.96)$ \\
\hline
\end{tabular}

Data are presented as $\mathrm{n}(\%)$ unless otherwise indicated. OR: odds ratio; $\mathrm{Cl}$ : confidence interval; JEM: job exposure matrix. ${ }^{*}$ : random intercept model adjusted for age, sex, type of study sample and smoking status at the time of completion of full-time education; ": referent category (unexposed to biological dust, mineral dust and gases or fumes); +. by occupation/ industry.

possible risk (0.82; CI 0.70-0.96) for asthma. Analyses restricted to respondents with asthma onset prior to versus after completion of full-time education were also similar. In these analyses, the population with asthma onset prior to completion of full-time education was at decreased risk of having a job with high (0.72; CI 0.57-0.92) or low (0.97; CI 0.79-1.19) exposure to dust, gases or fumes and working in occupations with known high risk $(0.78 ; 0.63-0.95)$ and possible risk $(0.80$; 0.62-1.02) for asthma.

\section{DISCUSSION}

The present findings provide novel evidence that, among young males and females in industrialised countries, preexisting asthma may influence whether or not they become employed in a job involving inhalation exposure to dust, gases or fumes or other asthma-related exposures. The finding that respiratory symptoms during childhood or even young adulthood may affect a person's career path has potentially important health implications. If occupation is a determinant of socioeconomic status, and epidemiological evidence demonstrates a relationship between socioeconomic status and health $[14,15]$, then the finding that asthma during the pre-employment stage of life may affect job selection suggests that it may also affect economic and health status during later life.
Development of appropriate pre-employment advice for students and young adults with respiratory symptoms could improve the occupational and health consequences in a population of workers at risk of work-exacerbated asthma.

These findings support and extend existing epidemiological evidence regarding respiratory health symptoms and job selection. In a study of teenage vocational trainees' respiratory health status and their preferred job choices, RADON et al. [16] reported nonsignificant associations between current and noncurrent asthma and selection of jobs with a low (current asthma: OR 1.50; non-current asthma: OR 0.70) or high (current asthma: OR 0.59; non-current asthma: OR 0.54) risk of asthma. In a study of hairdressing apprentices, lower prevalences of coughing and wheezing symptoms were reported among hairdressing apprentices compared to office apprentices [17]. It was noted that self-selection may have occurred if individuals with a history of allergic or respiratory symptoms chose to enter occupations without exposure to irritating or allergic agents [17]. The findings of these two studies [16, 17], as well as a review of the literature regarding the healthy worker effect in asthma [8], raise and evaluate an important hypothesis regarding respiratory symptoms and job choice. Together with the present findings, these studies suggest that, whether or not young adults with respiratory symptoms intentionally seek jobs with lower risks of asthma-related exposures, they may eventually find themselves in lower-risk jobs. Future research studies designed to follow cohorts of adolescents before and after they enter the workforce are needed to further assess this hypothesis.

The present results are based on analyses of data collected from ECRHS I, a large international population-based survey with standardised and validated questionnaire-based information regarding the prevalence of respiratory health symptoms and asthma-related risk factors [9]. Information about the age at which each respondent experienced their first attack of asthma compared to age of completion of full-time schooling was used as a proxy measure for onset prior to entering the workforce. The population without asthma before entering the workforce comprised individuals without any history of asthma and those whose asthma onset occurred after the completion of full-time education. Members of both populations were reportedly symptom-free at the time they completed their full-time education, and thus their job choices were not influenced by their asthma-related symptoms. Although a portion of this referent group went on to develop symptoms, these later symptoms should not have influenced any job selection that occurred at the time they completed their fulltime education. Data with which to validate questionnairebased responses about age at first asthma attack were not available. However, the mean age of the first reported asthma attack was 8 yrs (median 7 yrs) in the case population as compared to $28 \mathrm{yrs}$ (median $28 \mathrm{yrs}$ ) in the comparison population, suggesting that the asthma in the case population was predominantly childhood asthma. Additional information with which to verify age at asthma onset and information about the first job, occupation or industry that these individuals entered after completing their full-time education would strengthen the ability to draw conclusions regarding the causality of the associations reported here. 


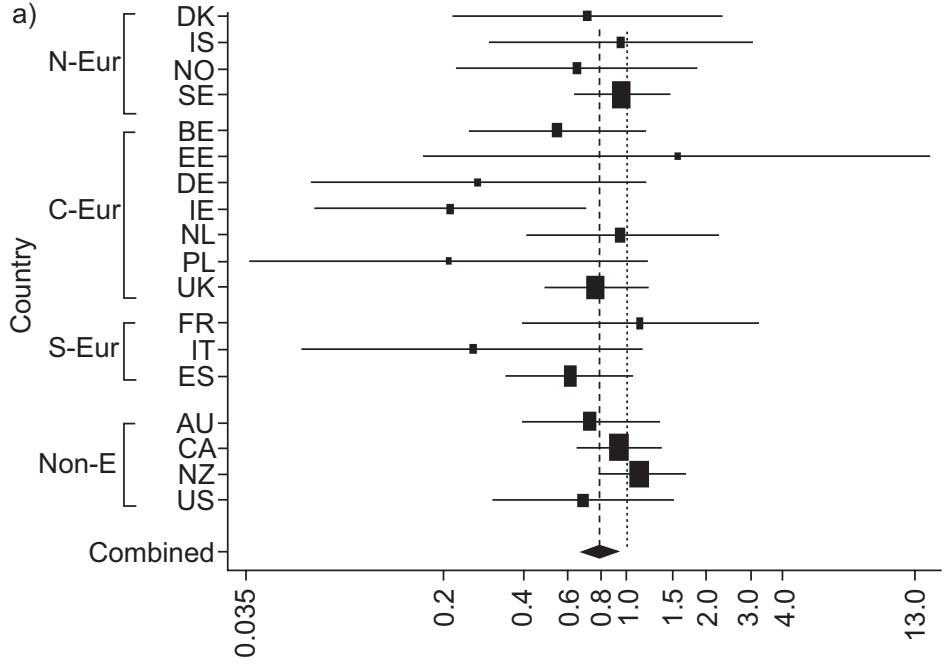

OR

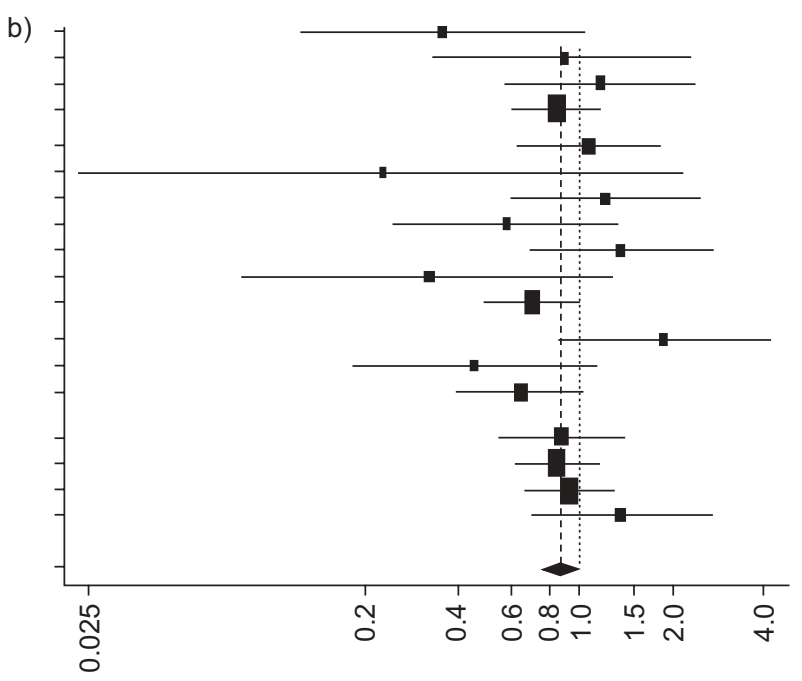

OR

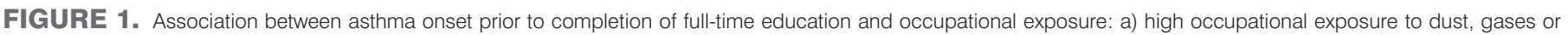

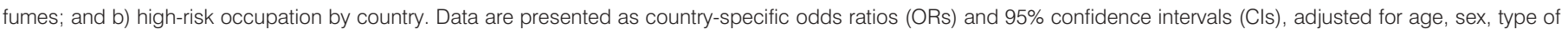

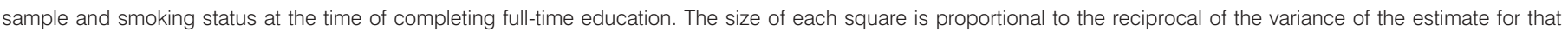

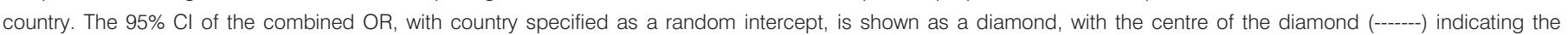

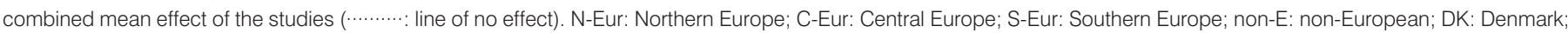

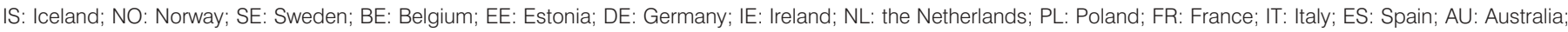
CA: Canada; NZ: New Zealand.

The same ECRHS I questionnaire data were used to identify which of the one or more jobs reported in the questionnaire the participant worked in first. That is, instead of using each participant's first job to classify inhalation exposures or increased risk of occupational asthma, the assigned exposure was based on using the earliest held job of those reported in the questionnaire. As a result, the estimate of exposure may have been assigned using the current or most recent job, a job that the respondent left because it affected their breathing or a job that the respondent indicated involved exposure to vapours, gas, dust or fumes. Several specific occupational exposure questionnaires and a job history identifying jobs held during the period between ECRHS I and ECRHS II were included in the follow-up of the ECRHS cohort [1], but neither the ECRHS I nor II data included sufficient information about participants' first jobs. Information about the first job selected after completing full-time education and about pre-employment health screening programmes that may be in place in exposed industries would strengthen the ability to draw conclusions about job selection, including intentional and unintentional selection.

Furthermore, if symptomatic workers entered jobs identified as exposed by the JEM or the a priori classification system at a similar frequency to the comparison population, but then sought positions with lower levels of exposure or protected themselves better because of their symptoms, then the present results may be lower and further from unity than what might have been observed had information about participants' first jobs been available. Hence, the present observation may reflect a traditional healthy worker survivor effect. Conversely, if symptomatic workers entered and stayed in jobs with lower levels of exposure, then the present findings should adequately reflect the healthy hire effect, rather than the healthy worker survivor effect. By using the earliest of the reported jobs, we intended to use information about the jobs held before such a job change was made. It should be noted that almost half $(48.6 \%)$ of the individuals in the present study population reported having left or changed jobs because it affected their breathing or having had a job with vapour, dust, gas or fume exposures. Using the JEM classification, 54\% were identified as exposed; using the high-risk occupation classification, $67 \%$ were identified as having high or possible risk. These data indicate that inhalation exposures are common in the general population, and there remains a need for healthcare providers, including paediatricians, school health personnel and counsellors or clinicians involved in workplace placement and screening programmes, to educate young people with asthma regarding the potential health risks related to their jobs.

Respondents may have had workplace experience before completing their full-time education. For example, in Germany, vocational training combines on-the-job training with traditional classroom education, and occupational selection among apprentices and vocational trainees may occur before students complete their full-time education. When asthma onset was categorised as having occurred before or after the age of $16 \mathrm{yrs}$, the results were similar. Categorising each individual according to onset prior to completion of fulltime education is likely to result in less misclassification of asthma status; therefore, only these findings are presented. The results justify assessment of the healthy hire effect in other cohorts; for example, cohorts of teenage students and apprentices, for whom the participants' first jobs or first vocational training experiences are known.

If asthma onset is associated with socioeconomic status, and socioeconomic status is associated with occupational exposure, 
then socioeconomic status may confound the relationship between asthma onset and occupational exposure. Previous analyses have used information about occupational status and age at the time of completing full-time education to categorise the respondents' social class [14, 15]. In the present analyses, occupation and education were explicitly used to create the main factors under investigation; thus it was not possible to further determine the potential independent influence of socioeconomic status or education. In the present data, the level of educational attainment was generally higher among respondents with asthma onset that occurred prior to completion of full-time education than among the remaining population. If educational level influences the ability of a person to select out of a job with potential inhalation exposure, then educational level could be an independent determinant of selection away from jobs with inhalation exposure that may initiate new asthma among previously symptom-free individuals or exacerbate pre-existing symptoms among those with a history of asthma. Therefore, although education is an important determinant of socioeconomic status, a limitation of the present analysis is that no additional information beyond education and occupation, which were used to create the independent and dependent variables respectively, is available in the ECRHS. If another unmeasured indicator of socioeconomic status confounds the relationship assessed here, then the present results and their ability to be generalised may be affected by this uncontrolled and/or residual confounding. Incorporation of additional metrics of social and economic standing into future studies of the healthy hire effect may reveal the extent to which confounding affects the present findings.

The healthy worker effect has largely been reported in cohorts of male workers [8]. Sex-related differences in the healthy worker effect have been reported among a cohort of fibre workers [18], although, in a meta-analysis of mortality among workers exposed to organic solvents, CHEN and SEATON [19] did not find a significant role for sex. Whether the healthy worker effect, including effects at the times of entering and departing selected occupations, operates in the same way and to the same degree in females is not known. The ECRHS I population includes females aged 20-44 yrs, an age range in which there are sex-based differences in the prevalence of respiratory symptoms [20,21]. An underestimation of occupational asthma among females has been suggested [22]. The present results do not support the hypothesis of sex-related differences in the association between asthma status and subsequent occupational exposure in the general population of young adults, but whether females may be differentially affected by the healthy hire or healthy worker survivor effects warrants further assessment in populations of employed females.

Research to investigate whether workers select jobs with or without specific exposures and whether healthy workers continue for longer in these jobs is required to more thoroughly understand job selection as a component of the healthy worker effect. Additional information about the role of socioeconomic status, the timing and severity of early asthma symptoms, and the extent to which young people are aware of the health risks associated with specific jobs is needed for a more comprehensive understanding of the effect estimates generated from epidemiological studies of occupational asthma and the healthy worker effect. Such information also has considerable potential to affect occupational public health practice if improvements in the understanding of the role of pre-existing health status in job selection leads to more appropriate pre-employment advice or early interventions for symptomatic individuals entering workplaces with dust and other inhalation exposures. Analysis of data from the ECRHS and other studies with detailed job history information will continue to improve understanding of the relationship between occupational exposure and asthma.

\section{SUPPORT STATEMENT}

The coordination of the European Community Respiratory Health Survey was supported by the European Commission (Brussels, Belgium). M. Mirabelli received funding from the US National Institutes of Health (Bethesda, MD, USA), grant number 1F32ES014142. The findings and conclusions in this report are those of the authors and do not necessarily represent the views of the National Institute for Occupational Safety and Health (NIOSH; Washington, DC USA). Mention of any company or product does not constitute endorsement by NIOSH.

\section{STATEMENT OF INTEREST}

None declared.

\section{ACKNOWLEDGEMENTS}

The affiliations of the present authors are as follows. M. Olivieri: Dept of Medicine and Public Health, Unit of Occupational Medicine, University Hospital of Verona, University of Verona, Verona; A. D'Errico: Servizio Regionale di Epidemiologia, Grugliasco; and S. Villani: Section of Medical Statistics and Epidemiology, Dept of Health Sciences, University of Pavia, Pavia (all Italy). M.C. Mirabelli: Dept of Epidemiology and Prevention, Division of Public Health Sciences, Wake Forest University School of Medicine, Winston-Salem, NC; and P. Henneberger: National Institute for Occupational Safety and Health, Centers for Disease Control and Prevention, Morgantown, WV (both USA). M.C. Mirabelli, E. Plana, J.M. Antó, J-P. Zock and M. Kogevinas: Centre for Research in Environmental Epidemiology; Municipal Institute of Medical Research; and Centro de Investigación Biomédica en Red de Epidemiología y Salud Pública; and J.M. Antó: Dept of Experimental and Health Sciences, Universitat Pompeu Fabra (all Barcelona, Spain). K. Radon: Unit for Occupational and Environmental Epidemiology \& NetTeaching, Institute for Occupational, Social and Environmental Medicine, Ludwig Maximilian University, Munich, Germany. P. Bakke: Dept of Thoracic Medicine, Haukeland University Hospital; and Institute of Medicine, University of Bergen (both Bergen, Norway). G. Benke: Dept of Epidemiology and Preventive Medicine, Monash University, Melbourne, Australia. H. Kromhout: Institute for Risk Assessment Sciences, Environmental Epidemiology Division, Utrecht University, Utrecht, the Netherlands. D. Norbäck and G. Wieslander: Dept of Medical Sciences, Occupational and Environmental Medicine, Uppsala University and University Hospital, Uppsala; and K. Torén: Depts of Allergology and Occupational and Environmental Medicine, Sahlgrenska University Hospital, Gothenburg (both Sweden). M. van Sprundel: Dept of Epidemiology and Social Medicine, University of Antwerp, Antwerp, Belgium. M. Kogevinas: Medical School, University of Crete, Heraklion, Greece.

\section{REFERENCES}

1 Kogevinas M, Zock JP, Jarvis D, et al. Exposure to substances in the workplace and new-onset asthma: an international prospective population-based study (ECRHS-II). Lancet 2007; 370: 336-341. 
2 Balmes J, Becklake M, Blanc P, et al. American Thoracic Society Statement: Occupational contribution to the burden of airway disease. Am J Respir Crit Care Med 2003; 167: 787-797.

3 McMichael AJ, Spirtas R, Kupper LL. An epidemiologic study of mortality within a cohort of rubber workers, 1964-72. J Occup Med 1974; 16: 458-464.

4 McMichael AJ, Haynes SG, Tyroler HA. Observations on the evaluation of occupational mortality data. J Occup Med 1975; 17: 128-131.

5 McMichael AJ. Standardized mortality ratios and the "healthy worker effect": scratching beneath the surface. J Occup Med 1976; 18: $165-168$.

6 Fox AJ, Collier PF. Low mortality rates in industrial cohort studies due to selection for work and survival in the industry. Br J Prev Soc Med 1976; 30: 225-230.

7 Vinni K, Hakama M. Healthy worker effect in the total Finnish population. Br J Ind Med 1980; 37: 180-184.

8 Le Moual N, Kauffmann F, Eisen EA, et al. The healthy worker effect in asthma - work may cause asthma, but asthma may also influence work. Am J Respir Crit Care Med 2008; 177: 4-10.

9 Burney PGJ, Luczynska C, Chinn S, et al. The European Community Respiratory Health Survey. Eur Respir J 1994; 7: 954-960.

10 Office of Population Censuses and Surveys, Classification of Occupations 1980. London, Her Majesty's Stationary Office, 1980.

11 Sunyer J, Kogevinas M, Kromhout $\mathrm{H}$, et al. Pulmonary ventilatory defects and occupational exposures in a population-based study in Spain. Am J Respir Crit Care Med 1998; 157: 512-517.

12 de Vocht F, Zock JP, Kromhout H, et al. Comparison of selfreported occupational exposure with a job exposure matrix in an international community-based study on asthma. Am J Ind Med 2005; 47: 434-442.
13 Kogevinas M, Anto JM, Sunyer J, et al. Occupational asthma in Europe and other industrialised areas: a population-based study. Lancet 1999; 353: 1750-1754.

14 Basagaña X, Sunyer J, Kogevinas $M$, et al. Socioeconomic status and asthma prevalence in young adults - the European Community Respiratory Health Survey. Am J Epidemiol 2004; 160: 178-188.

15 Ellison-Loschmann L, Sunyer J, Plana E, et al. Socioeconomic status, asthma and chronic bronchitis in a large community-based study. Eur Respir J 2007; 29: 897-905.

16 Radon K, Huemmer S, Dressel H, et al. Do respiratory symptoms predict job choices in teenagers? Eur Respir J 2006; 27: 774-778.

17 Iwatsubo Y, Matrat M, Brochard P, et al. Healthy worker effect and changes in respiratory symptoms and lung function in hairdressing apprentices. Occup Environ Med 2003; 60: 831-840.

18 Lea CS, Hertz-Picciotto I, Andersen A, et al. Gender differences in the healthy worker effect among synthetic vitreous fiber workers. Am J Epidemiol 1999; 150: 1099-1106.

19 Chen R, Seaton A. The influence of study characteristics on the healthy worker effect: a multiple regression analysis. Occup Med (Lond) 1996; 46: 345-350.

20 Knudsen TB, Thomsen SF, Nolte $\mathrm{H}$, et al. A population-based clinical study of allergic and non-allergic asthma. J Asthma 2009; 46: 91-94.

21 Dimich-Ward H, Camp PG, Kennedy SM. Gender differences in respiratory symptoms - does occupation matter? Environ Res 2006; 101: 175-183.

22 Kogevinas M, Anto JM, Soriano JB, et al. The risk of asthma attributable to occupational exposures. A population-based study in Spain. Spanish Group of the European Asthma Study. Am J Respir Crit Care Med 1996; 154: 137-143. 